\title{
On the Plastic Wave Propagation Along the Specimen Length in SHPB Test
}

\author{
Z.G. Wang $\cdot$ L.W. Meyer
}

Received: 20 May 2009/Accepted: 7 September 2009/Published online: 2 October 2009

(C) The Author(s) 2009. This article is published with open access at Springerlink.com

\begin{abstract}
To observe the plastic wave propagation, an experimental setup is designed with a SHPB facility and a high speed digital camera. Two types of OFHC copper were selected as specimen materials: in the cold work condition and after total annealing, which represent non strain hardening and strain hardening material respectively. The rise time of incident impulse in the SHPB test is relevant to bar's radius. A maximum allowable specimen length and a maximum allowable impact velocity (MAIV) of striker are proposed for the SHPB test. The propagation of plastic waves is observed along specimen length at the beginning of specimen's plastic deformation in SHPB test. However, for both types of material, no plastic wave motion is caught along specimen length for large plastic strain level. Side confinement effect of friction is found to be significant, even with lubricant in the experiment.
\end{abstract}

Keywords Split Hopkinson pressure bar (SHPB) .

Plastic wave - Equilibrium - Specimen's geometry .

Impact velocity OFHC copper

\section{Introduction}

It is becoming more and more important to understand the mechanical behavior of materials under external high rate loading in industrial application and scientific research.

Z.G. Wang $(\bowtie) \cdot$ L.W. Meyer

Institute of Material and Impact Engineering Laboratory,

Faculty of Mechanical Engineering and Processing,

Chemnitz University of Technology,

09107 Chemnitz, Germany

e-mail: wangzonggang@gmail.com

URL: www.wsk.tu-chemnitz.de
Experimentally, after Hopkinson and Kolsky's early work [1-6], the Split Hopkinson pressure bar (SHPB) gradually became a widely accepted facility to test materials' mechanical properties under dynamic loading at the strain rate of $10^{3}-10^{4} / \mathrm{s}$ in modern mechanical laboratory [7-12]. The SHPB setup usually consists of striker, incident bar and transmitted bars, which are all the same diameter cylindrical bars, made from hard materials. In the test, the specimen is sandwiched between the incident and transmitted bars, then the striker hits the end of incident bar in the axial direction with an initial velocity $V$. A trapezoidal incident stress impulse is generated and propagates down the incident bar. When the length of striker is short compared with the total length of incident bar and transmitted bar:

$\sigma_{i}=\frac{1}{2} \rho_{b a r} c_{b a r} V$

And the duration of the created stress impulse is:

$\Delta t=\frac{2 L_{s}}{c_{\text {bar }}}$

Where $\rho_{\text {bar }}$ is mass density of the bar; $c_{b a r}=\sqrt{E_{b a r} / \rho_{b a r}}$ is the elastic longitudinal stress wave velocity in the bar; $E_{\text {bar }}$ is the Young's modulus of the bar; $V$ is the velocity of striker; $L_{\mathrm{s}}$ is the length of the striker.

In laboratory application, if the Young's modulus of the bar is known, experimenters usually can determine if the generated experimental incident impact pulse is good quality or not, by calculating out the velocity and length of the striker from the recorded incident impulse. The generated elastic stress pulse then propagates along the incident bar with the longitudinal elastic wave velocity. Transmitted and reflected stress pulses are generated and 
propagated in the transmitted bar and incident bar respectively, when the incident impulse loads the specimen. When there is force equilibrium between the specimen's incident and transmitted sides (relationship of incident, reflected and transmitted signals is equation (3)), the specimen is uniformly deformed, and the stress-strain curves of the material can be determined with one dimensional assumption from equations (4) and (5):

$\varepsilon_{t}=\varepsilon_{i}+\varepsilon_{r}$

$\sigma=\frac{A_{b a r} E_{b a r} \varepsilon_{t}}{A_{s p}}$

$\dot{\varepsilon}=\frac{2 c_{b a r} \varepsilon_{r}}{L}$

where $\varepsilon_{\mathrm{t}}, \varepsilon_{i}$ and $\varepsilon_{\mathrm{r}}$ are the values of transmitted, incident and reflected signals in the bars respectively; $\dot{\varepsilon}$ is the loading strain rate of the tested specimen; $L$ is the initial length of the tested specimen.

If there is no force equilibrium for the two sides of specimen in the SHPB test, it means the measurement is uncertain and no calculation can be done from the recorded signals, using the above equations. So generally in the SHPB test, the specimen is dynamically and uniformly deformed, the only difference between quasi-static test and so-called dynamic test in the SHPB test is deforming rate (i. e. strain rate).

The above classic analysis of SHPB test is widely applied by experimenters to determine the mechanical behavior of tested materials under dynamic loading. Scientists try to increase the striker's velocity and reduce the specimen's dimension, as far as they can, to get higher strain rate loading on the specimen [13].

However, the above data processing method for the SHPB test is based on two assumptions: one is force equilibrium on both sides of the specimen, the other is the one dimensional uniformly deformed specimen. About the force equilibrium, to minimize experimental errors, one can improve the recorded strain gage signals by applying experimental techniques, such as keeping good contact between bars and specimen, reducing the friction between bars and supporters, keeping bars well coaxial and so on. But is the specimen really one dimensional uniformly deformed in SHPB test as a quasi-static test? In the quasistatic test, the specimen is deformed at a very low strain rate $\left(10^{-3} / \mathrm{s}\right)$, so loading stress waves have sufficient time to pass and reflect along the specimen length and the one dimensional assumption can be easily satisfied. On the other hand, in SHPB test, no matter what the specimen's material is and what the specimen geometry is, initially the stress waves will always travel along the specimen from the incident side to the transmitted side, at a velocity comparable to that of the loading. As we know, the elastic longitudinal wave velocity in solids is around 4,000 $5,000 \mathrm{~m} / \mathrm{s}$, so for a specimen with $5-10 \mathrm{~mm}$ length, the stress wave can pass it in $1 \mu \mathrm{s}$ or $2 \mu \mathrm{s}$, if the stress waves travel along the specimen length with the elastic longitudinal wave velocity for the whole loading time. So comparing with the hundred-microsecond loading time of the incident impulse, this passing time along specimen length of the stress waves is sufficiently short, and the specimen can be uniformly one dimensionally deformed as in the quasi-static test.

However, plastic wave theory was proposed and developed in 1950's [14-16]. In the theory, stress waves propagate in the medium with the velocity, which is related to the slope of material's true stress-strain curve (modulus $E$ ) and mass density. In equation (6), modulus $E$ can be either the elastic Young's modulus or the plastic modulus respectively, when the material is elastically or plastically deformed:

$E=\frac{\partial \sigma_{\text {true }}}{\partial \varepsilon_{\text {true }}}$

As shown in Fig. 1, for a specific material, the plastic modulus is much smaller than the elastic modulus. Thus, when specimen undergoes plastic deformation, the stress wave velocity will be significantly slower, especially for non strain hardening materials. So in an SHPB test, the time for the stress wave passing and reflecting the specimen length and building up force equilibrium maybe can't be

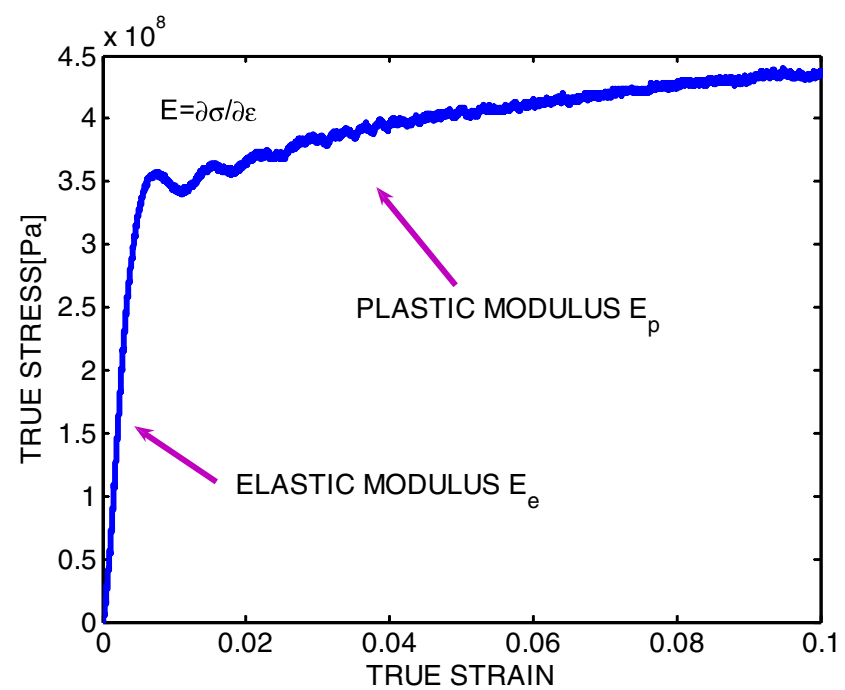

Fig. 1 A stress-strain diagram to show a material's different Moduli in the elastic and plastic deformation domain 
treated as short (compared with dynamic loading time), which might lead to a non-uniform deformation along the specimen length and do not fulfill the equilibrium condition at the beginning of specimen's plastic deformation in the SHPB test.

Here, by taking account into plastic wave propagation effect, we'll investigate the data processing method of the SHPB test again and try to determine the technique and specimen geometry limitations in the SHPB test. Afterwards, an experimental setup is built with a SHPB system and a high speed digital camera to experimentally observe the plastic wave propagation along specimen length during dynamic loading. Then a virtual SHPB setup is numerically modeled by commercial software to authenticate and explain the theoretical results. In the end, discussion and conclusion are made to interpret newly developed results.

\section{Theoretical Analysis}

In SHPB test, when the striker hits the incident bar in the axial direction, a trapezoidal stress impulse is generated and then propagates along the incident bar (Fig. 2). From an elastic wave analysis point of view, what composes the incident impulse and what the strain gages on the bar can record are the stress wave components with a longitude elastic velocity $\sqrt{E_{b a r} / \rho_{b a r}}$ in the axial direction. Kolsky and Davies did full frequency analysis on elastic stress wave propagation in SHPB test by using the Pochhammer and Chree equations [17-21], which can successfully describe such wave motions in an elastic cylindrical medium $[2,3]$. They concluded that wave components,

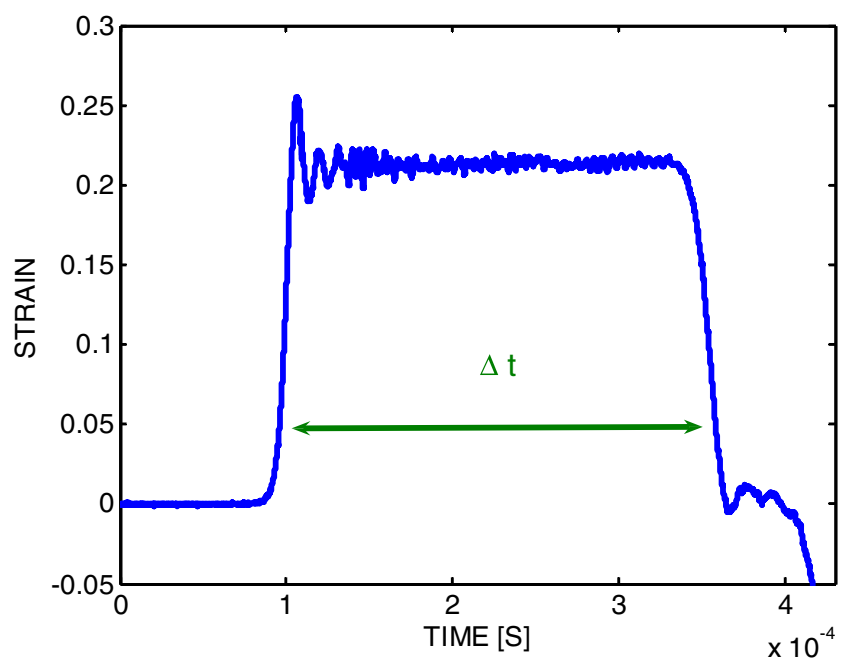

Fig. 2 The incident stress impulse recorded by strain gages on the incident bar in SHPB test [the amplitude and time duration can be calculated by equations (1) and (2) respectively] which propagate along the bar with the elastic wave velocity $\sqrt{E_{\text {bar }} / \rho_{\text {bar }}}$, are only those with long wave lengths $r / \Lambda<0.1$ (i.e. lower frequencies. $\Lambda$ is wave length; $r$ is the radius of bar) $[2,3]$. So when the incident stress impulse travels along the elastic cylindrical bar, it's distorted and dissipated. Finally, what strain gages record and what loads are applied to the specimen are only those wave components with long wave lengths. All other wave components with short wave lengths or high frequencies are filtered out.

In addition, from linear frequency analysis theory, for a step signal with a rising time $T_{\mathrm{r}}$ and a duration time $\Delta t$ (shown in Fig. 3), we have the following relationship:

$T_{r} \approx T_{\min } / 2$

$T_{\max } \approx \Delta t / 2$

where $T_{\min }$ and $T_{\max }$ are the minimum and maximum period of wave components in the signal respectively. So by applying the above linear wave analysis result, the incident impulse has following properties:

Wave length window: $10 r<\Lambda<4 L_{s}$

Period window: $\frac{10 r}{c_{b a r}}<T<\frac{4 L_{s}}{c_{b a r}}$

Frequency window: $\frac{\pi}{2 L_{s}}<\omega<\frac{\pi}{5 r}$

And the rise time of incident impulse is around:

$T_{r} \approx \frac{5 r}{c_{b a r}}$

From equation (12), for the $19.7 \mathrm{~mm}$ diameter steel SHPB system in the Material and Impact Engineering Laboratory of the Faculty of Mechanical Engineering Chemnitz University of Technology, the rise time of the incident impulse should be: $T_{r} \approx 11 \mu \mathrm{s}$. By contrast, a typical experimental incident signal recorded by strain gages is shown in Fig. 4, of which $T_{\mathrm{r}}$ is about $12 \mu \mathrm{s}$. The experimental results match the theoretical analysis very well.

It's widely accepted that force equilibrium on the specimen in SHPB test is established in this rising time 


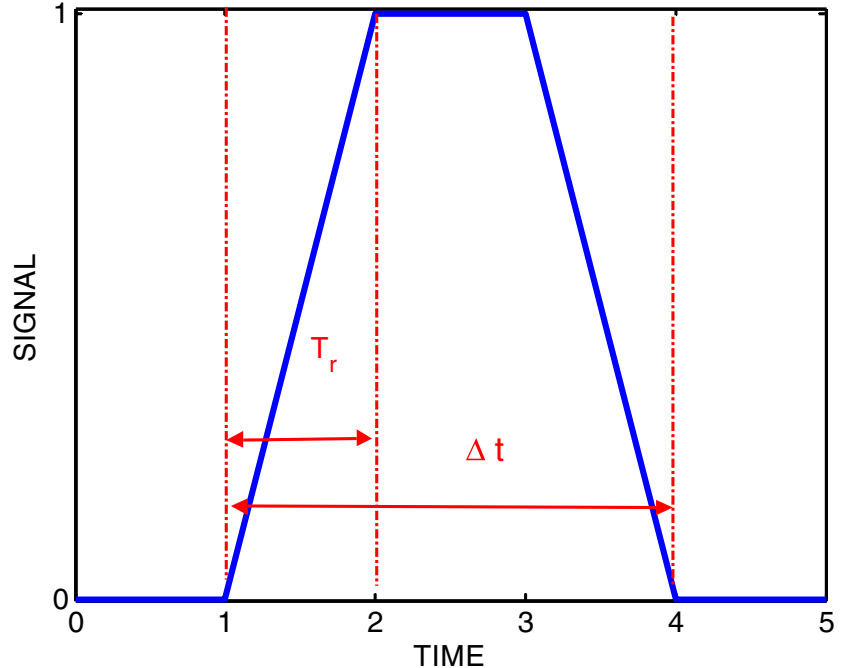

Fig. 3 A step signal with a rising time $T_{r}$ and a duration time $\Delta t$

duration. So a maximum allowable specimen length is obtained:

$L_{\max }=\frac{1}{n} \frac{c_{s p}}{c_{b a r}} 5 r \approx \frac{5 r}{n}$

where $c_{\mathrm{sp}}$ is the elastic wave velocity in specimen; $n$ is the number of times stress waves travel along the specimen's length, to build the force equilibrium, which is believed to be three or four times.

Once force equilibrium is established, equations (3), (4) and (5) are immediately valid. When the specimen's deformation is just passing the yield point of the specimen's material, the following classic relationship is satisfied from one dimensional Hooke's law:

$\sigma_{y}=E_{s p} \varepsilon_{y}$

$\sigma_{y}$ and $E_{\mathrm{sp}}$ are the yield stress and Young's modulus of the specimen respectively.

At the yield point, if the strain rate $\dot{\varepsilon}$ is known, the loading time on the specimen can be calculated as:

$t_{y}=\frac{\sigma_{y}}{E_{s p} \dot{\varepsilon}}$

From Von Karman's plastic wave theory, the velocity of the stress wave will immediately reduce from the elastic wave velocity to the plastic wave velocity, when the specimen yields and starts plastically deforming. So in the time duration $t_{y}$, the stress wave at least has to pass the whole specimen and reach the transmitted side of the specimen. The specimen length should fulfill the following equation:

$L \leq c_{s p} t_{y}$

Now applying the data processing method of SHPB and substituting equations (3), (5) and (15) into the above equation, we have:

$\frac{c_{s p} \sigma_{y}}{2 c_{b a r} E_{s p}\left(\varepsilon_{i}-\varepsilon_{t}\right)} \geq \frac{L}{L}=1$

From equation (4), when the specimen is yielding, the transmitted signal obeys the following relationship:

$\varepsilon_{t}=\frac{A_{s p}}{A_{b a r} E_{b a r}} \sigma_{y}$

Furthermore, from one-dimensional Hooke's law and equation (1), the strain of the incident impulse is:

$\varepsilon_{i}=\frac{\rho_{b a r} c_{b a r} V}{2 E_{b a r}}$

Substituting equations (18), (19) into equation (17), and doing simplification and rearrangement, we obtain:

$V \leq\left(\frac{1}{2} \frac{\rho_{b a r} c_{b a r}}{\rho_{s p} c_{s p}}+\frac{d_{s p}^{2}}{d_{b a r}^{2}}\right) \frac{2 \sigma_{y}}{\rho_{b a r} c_{b a r}}$

where $d_{\mathrm{sp}}$ and $d_{\mathrm{bar}}$ are diameter of the specimen and bar respectively.

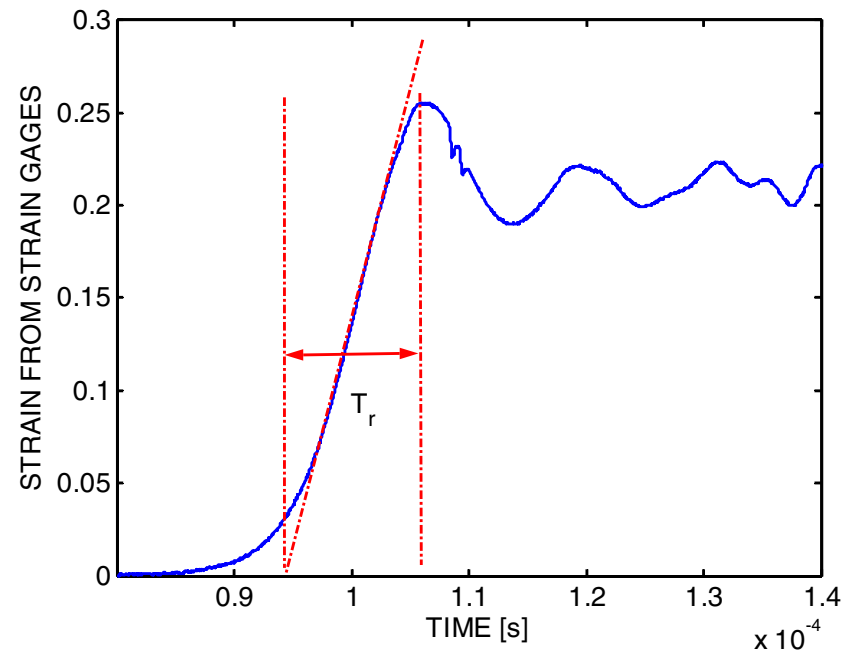

Fig. 4 An incident impulse measured by strain gages on the incident bar of the $19.7 \mathrm{~mm}$ diameter SHPB facility in our laboratory 
Table 1 Mechanical constants of selected typical engineering materials

\begin{tabular}{lllll}
\hline Material & $\begin{array}{l}\text { Young's modulus } \\
{[\mathrm{GPa}]}\end{array}$ & $\begin{array}{l}\text { Mass density } \\
{\left[\mathrm{kg} / \mathrm{m}^{3}\right]}\end{array}$ & $\begin{array}{l}\text { Longitude wave } \\
\text { velocity }[\mathrm{m} / \mathrm{s}]\end{array}$ & $\begin{array}{l}\text { Yielding } \\
\text { stress }[\mathrm{MPa}]\end{array}$ \\
\hline Steel & 181.5 & 7970 & 4772 & 2000 \\
Tungsten & 380 & 19300 & 4437 & 1700 \\
Ti6A14V & 113.8 & 4430 & 5068 & 970 \\
Al6063 & 69 & 2700 & 5055 & 300 \\
Mg AM50 & 45 & 1770 & 5042 & 110 \\
OFHC copper & 110 & 8960 & 3503 & $30 / 320$ \\
\hline
\end{tabular}

Now in equation (20), there are only material constants of specimen and bar in the right hand. Let

$C_{1}=\frac{1}{2} \frac{\rho_{b a r} c_{b a r}}{\rho_{s p} c_{s p}}$

$C_{2}=\frac{d_{s p}^{2}}{d_{b a r}^{2}}$

Finally we have:

$V \leq\left(C_{1}+C_{2}\right) \frac{2 \sigma_{y}}{\rho_{\text {bar }} c_{\text {bar }}}$

Equation (23) shows there is a maximum allowable impact velocity (MAIV) of striker in the SHPB test. When

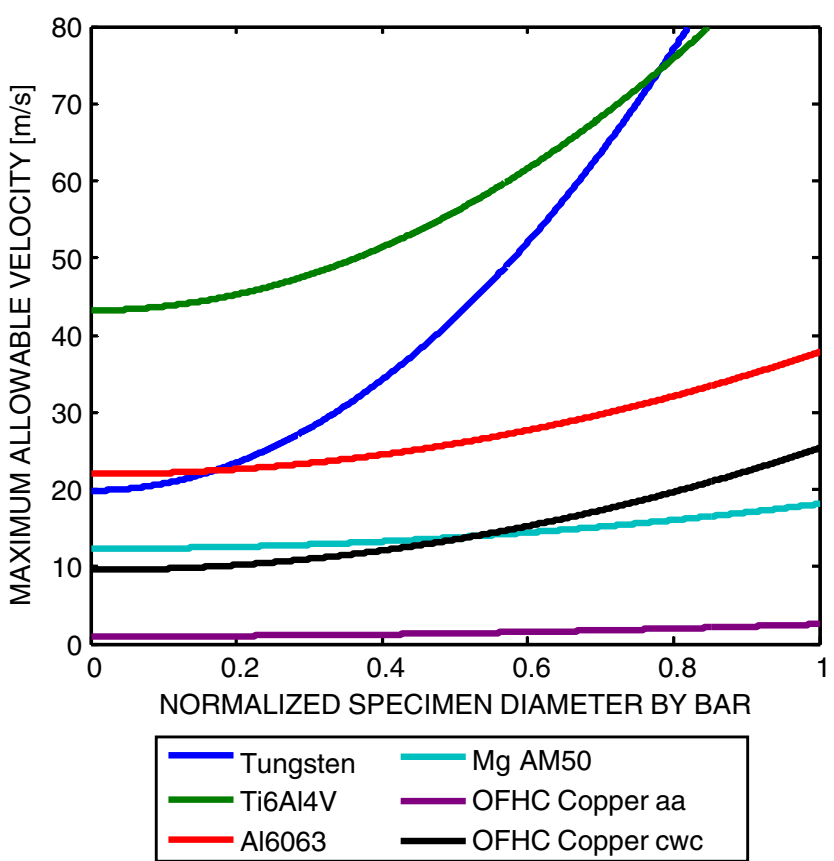

Fig. 5 MAIV changes as a function of normalized specimen's diameter, which is equal to $d_{\mathrm{sp}} / d_{\mathrm{bar}}$ for several typical engineering materials (OFHC copper $a a$ means after annealing; OFHC copper $c w c$ means in a cold work condition) the striker's velocity is lower than MAIV, the condition for building up force equilibrium is fulfilled; so the specimen can be uniformly deformed in the SHPB test. On the other hand, if the striker's velocity is higher than MAIV, incident side of specimen is always plastically deformed before the transmitted side of specimen yields; i.e. the specimen undergoes non-uniform plastic deformation, which may lead to the SHPB experiment being invalid.

In equation (23), both $C_{1}$ and $C_{2}$ are dimensionless parameters and have clear physical meaning. $C_{1}$ represents the relative material property $\rho c$, and $C_{2}$ is the square of diameter ratio of specimen and bar, which describes the specimen's relative geometrical dimension in one specific SHPB test. In addition, MAIV is proportional to the yield stress of the specimen material, which means MAIV will be rather low, if the test specimen's yield stress is too low. For further discussion, relevant mechanical properties of the $19.7 \mathrm{~mm}$ diameter steel SHPB system in our Laboratory and several selected common engineering alloys are presented in Table 1.

Figure 5 shows the variation of MAIV as a function of the specimen' normalized diameter by that of the bar $d_{\mathrm{sp}}$ / $d_{\text {bar. }}$ Since normally the specimen's diameter is smaller than that of the bar, the value of $C_{2}$ should vary from zero to 1 . In the figure, for soft materials (low yield and plastic flow

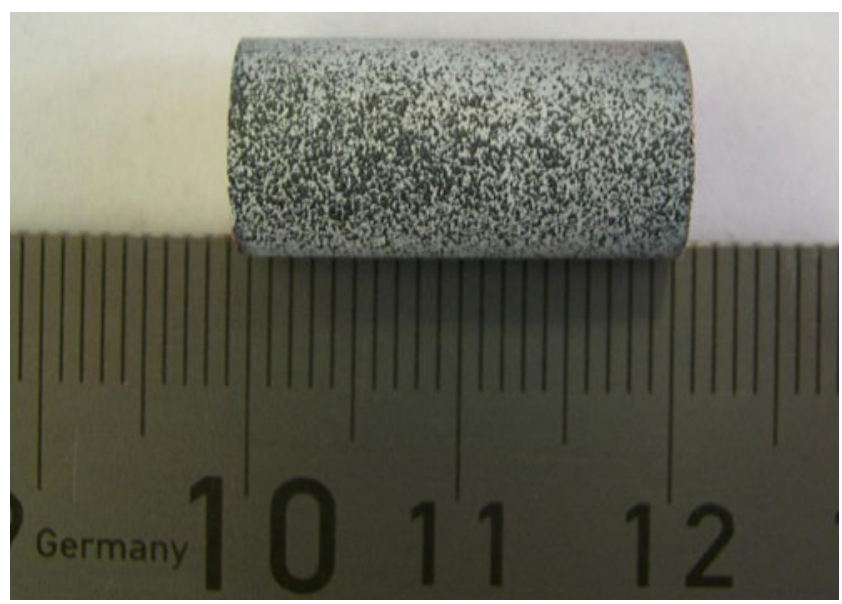

Fig. 6 An OFHC copper specimen with a white background and black dot pigment surface before the test 


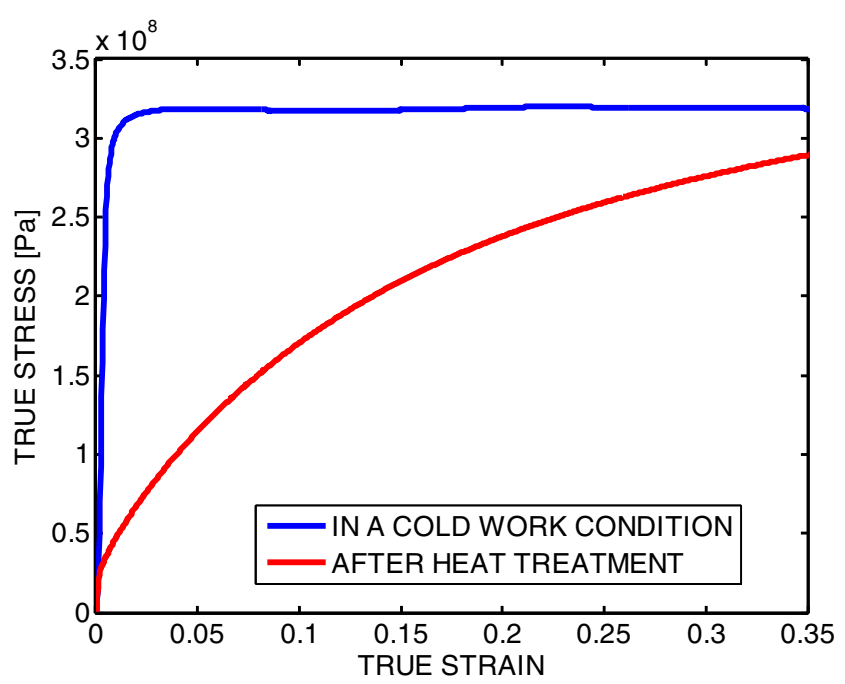

Fig. 7 Static stress-strain curves of OFHC copper specimens in a cold work condition and after total annealing

stress compared with bar material): e. g. MgAM50, Al6063, and OFHC copper, MAIV isn't sensitive to the variation of specimen diameter. Yield stress of the tested material becomes a dominant parameter, for example, the MAIV for OFHC copper after total annealing is only around $1 \mathrm{~m} / \mathrm{s}$ to $2 \mathrm{~m} / \mathrm{s}$, which corresponds to a rather low yield stress $30 \mathrm{MPa}$. So it becomes quite understandable that very soft materials aren't suitable for SHPB test because of their low yield stresses, no matter what the specimen geometry is. On the other hand, for hard materials (compared with bar material): Tungsten and Ti6Al4V, for which the value of $\rho c$ is equivalent to hard steel, thus, relative geometrical parameter becomes significant for MAIV. MAIV increases significantly with specimen diameter. MAIV varies from $20 \mathrm{~m} / \mathrm{s}$ to $100 \mathrm{~m} / \mathrm{s}$ for Tungsten and from $40 \mathrm{~m} / \mathrm{s}$ to $90 \mathrm{~m} / \mathrm{s}$ for Ti6Al4V. In such case specimen diameter becomes critical in the SHPB test and should be carefully chosen.

\section{Experimental Observation}

The $19.7 \mathrm{~mm}$ diameter SHPB in our laboratory was used to observe plastic wave propagation along specimens using a high speed digital camera (REDLAKE HGK100), which has a $50 \mu \mathrm{s}$ frame rate and is assembled to focus on the specimen's half cylindrical surface during the test. According to the above theoretical analysis and because of its low plastic wave velocity [16, 22, 23], OFHC copper was selected as experimental specimen material. The specimen geometry was chosen as 10-20 (mm) diameter-length cylinder. In the test, the specimen cylindrical surface was covered by a thin layer of white background and black dot pigments (shown in Fig. 6).

Both the oscilloscope for the strain gages on the bars and the camera are triggered by $5 \%$ increasing incident strain impulse and a software post trigger was also designed for the camera to enhance the camera's frame resolution. So half full cylindrical surface photographs of the experimental specimen can be recorded simultaneously with the strain signals from the SHPB test, and half cylindrical strain field can be obtained from the photographs afterwards by an optical deformation and strain measurement software: ARAMIS V6.0.1-3, which is an optical technique to measure the deformation and strain of the surface of specimen and can recognize the surface structure of the measuring object in digital camera images and allocates coordinates to the image pixels.

The OFHC copper specimens are classified to two groups: as received in a cold work condition and after total annealing heat treatment. Static true stress-strain curves for these two types of OFHC copper specimens are shown in Fig. 7, and necessary technique coefficients for specimen and trigger in the experiment are shown in Table 2. For the OFHC copper specimens in the cold work condition, yield stress is around $300 \mathrm{M} \mathrm{Pa}$ and plastic stress almost remains constant regardless of plastic strain level, which is a typical non-
Table 2 Technique data of OFHC copper specimens and triggers in the SHPB test with camera

\begin{tabular}{llllr}
\hline Specimen & Material & $\begin{array}{l}\text { Diameter/length } \\
{[\mathrm{mm} / \mathrm{mm}]}\end{array}$ & $\begin{array}{l}\text { Trigger } \\
\text { level }[\mathrm{mV}]\end{array}$ & $\begin{array}{l}\text { Post trigger time } \\
\text { of the camera }[\mu \mathrm{s}]\end{array}$ \\
\hline$\# 1$ & Cold work condition & $10 / 20$ & 638 & 0 \\
$\# 2$ & Cold work condition & $10 / 20$ & 638 & 10 \\
$\# 3$ & Cold work condition & $10 / 20$ & 638 & 20 \\
$\# 4$ & Cold work condition & $10 / 20$ & 638 & 30 \\
$\# 5$ & Cold work condition & $10 / 20$ & 638 & 40 \\
$\# 7$ & After annealing & $10 / 20$ & 638 & 0 \\
$\# 8$ & After annealing & $10 / 20$ & 638 & 10 \\
$\# 10$ & After annealing & $10 / 20$ & 638 & 20 \\
\hline
\end{tabular}




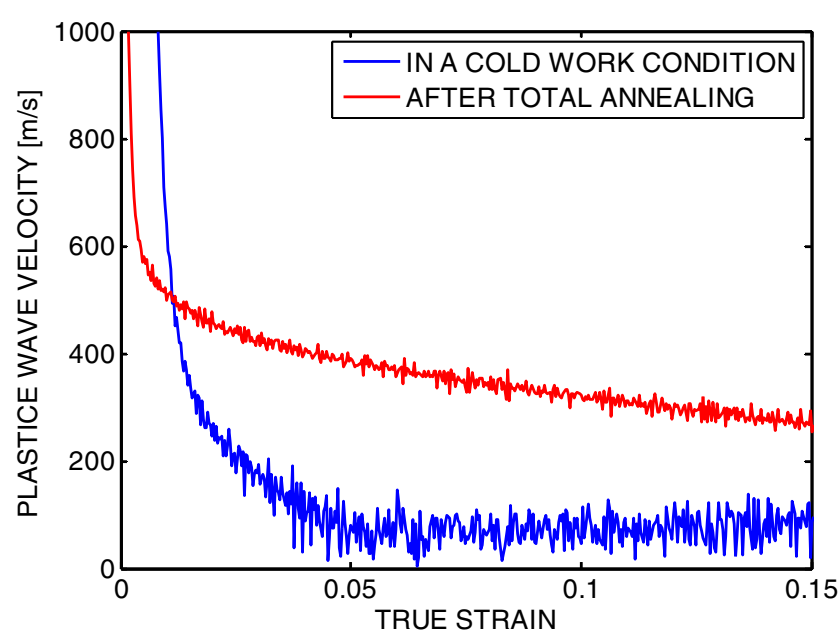

Fig. 8 Theoretical one dimensional plastic wave velocities as a function of true strain for the two type OFHC copper specimens (in the cold work condition and after total annealing), calculated from true stress-strain curves in Fig. 7

strain hardening material and may lead to a very low plastic wave velocity (especially at the large plastic strain level) from Von Karman's one dimensional plastic wave theory. By contrast, the OFHC copper specimens after total annealing heat treatment have a very low yield stress $30 \mathrm{M} \mathrm{Pa}$ and plastic stress increases with plastic strain level, which is a typical strain hardening material. The strain hardening effect is significant and plastic wave velocity reduces from the elastic value more moderately than OFHC copper specimens in the cold work condition, once specimen starts plastic deformation. For these two types of OFHC copper, theoretical plastic wave velocities, calculated from Von Karman's theory, are shown in Fig. 8.

A schematic of the SHPB in our laboratory is shown in Fig. 9 and necessary parameters are shown in Table 3 to synchronize the photograph frames of the camera and the strain gage signals. By keeping the camera time scale static, and moving the strain gage signals recorded from the bars, we can synchronize the results from the camera and strain gage signals of the SHPB as:

$T_{\text {incid }}=T_{\text {trig }}+L_{\text {bar }} / 2 c_{\text {bar }}-T_{p_{-} \text {trig }}$

$$
\begin{aligned}
& T_{\text {refl }}=T_{\text {trig }}-L_{b a r} / 2 c_{b a r}-T_{p_{-} \text {trig }} \\
& T_{\text {trans }}=T_{\text {trig }}-L_{s g} / c_{b a r}-T_{p_{-} \text {trig }}-L / c_{s p}
\end{aligned}
$$

Where, $T_{\text {incid }}, T_{\text {refl }}$ and $T_{\text {trans }}$ are the time duration to be shifted for those signals respectively; $T_{\mathrm{p}_{-} \text {trig }}$ is the camera's post trigger time. As an example, Figs. 10 and 11 show the recorded and shifted (with the mark of camera frames) SHPB signals of specimen \#1 respectively. The half cylindrical strain fields of specimen $\# 1$ are shown in Fig. 12 with a $50 \mu$ s time step, which are obtained from photographs after imaging processing using software ARAMIS V6.0.1-3. In the software, the half cylindrical surface of the specimen is divided into $10 \times 20$ pixels, i. e. one pixel is approximately one square millimeter [Fig. 12 (a)]. As the specimen is deformed, each pixel also moves and deforms. The software can track each pixel displacement, calculate the deformation, and display the whole half cylindrical strain field of the specimen. However, in the experiment some pixels in the strain field may be missed, especially for large plastic strain levels [Fig. 12(d), (e) and (f)], because part of the pigments on the cylindrical surface sometimes fly away during dynamic loading. Since our aim is to observe the propagation of plastic waves along the specimen length in an SHPB test and test Von Karman's one-dimensional plastic wave theory, the variation of strain along the specimen length is the most interesting result. So the pixel path along the specimen length in the middle of the half cylindrical strain field is selected to represent the strain status of specimen, to minimize error from the camera's depth of field.

For the OFHC copper specimens in the cold work condition, Fig. 13 shows the strain distribution of the defined pixel path along its normalized length. Solid curves are from frame 3 to frame 9 of specimen $\# 3$, which corresponds to the red dashed-dot line in Fig. 11. As the post trigger is designed to increase the resolution of the camera, the corresponding results (dashed lines) of specimens \#1, \#2, \#4 and \#5 are inserted between the curves of frame 3 and frame 4 of specimen \#3 with a $10 \mu$ s time
Fig. 9 Schematic of the SHPB setup in our laboratory of TU-Chemnitz

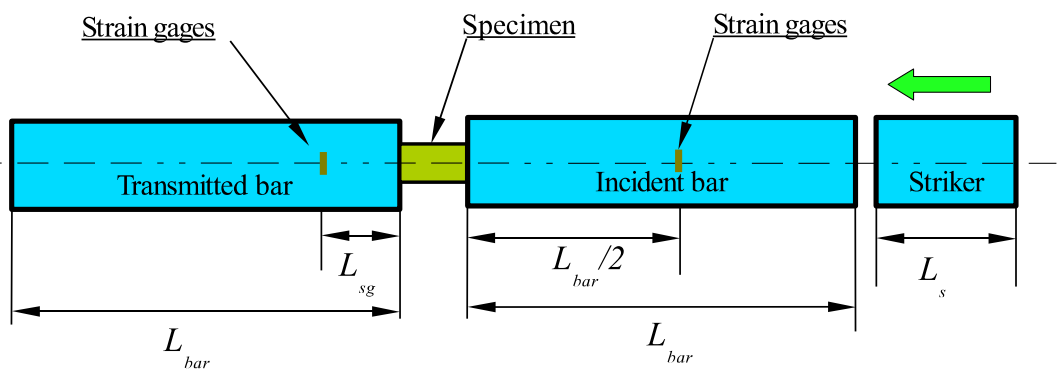


Table 3 The necessary geometrical parameters of the bar and specimen for synchronization of digital camera and strain gage signals [mm]

\begin{tabular}{lllllll}
\hline Name & $L_{s}$ & $L_{b a r}$ & $L_{s g}$ & Length of specimen $L$ & Diameter of bar $d_{b a r}$ & Diameter of specimen $d_{s p}$ \\
\hline Value & 598 & 1475 & 150 & 20 & 19.7 & 10 \\
\hline
\end{tabular}

interval. In the figure, initially the specimen is plastically deformed from the incident side to the transmitted side, and the plastic strain level decreases with distance to the incident end of specimen. It clearly shows the existence and propagation of one dimensional plastic wave along the specimen length. But when the strain level is around $4 \%$ to $5 \%$, the plastic deformation becomes rather uniform along the specimen length. Afterwards, the plastic strain at the specimen's two ends is gradually smaller than that in its middle, when the plastic strain level goes larger. This trend is accumulated and becomes more and more severe, until the end of loading, which finally leads a barrel shaped deformed specimen, because the lubricant between the bars and specimen is squeezed out and the side confinement effect of the friction between specimen and bars becomes significant.

For the OFHC copper specimens after total annealing heat treatment, the SHPB strain signals synchronized with camera frame mark for specimen \#9 are shown in Fig. 14. The strain distribution of the defined pixel path along the normalized specimen length is also shown in Fig. 15, obtained by the same method used for the previous OFHC copper specimens in the cold work condition (Fig. 13). Compared with OFHC copper in a cold work condition, similar material plastic behavior is obtained for the specimens after total annealing heat treatment, although it is a strain hardening material (Fig. 15).

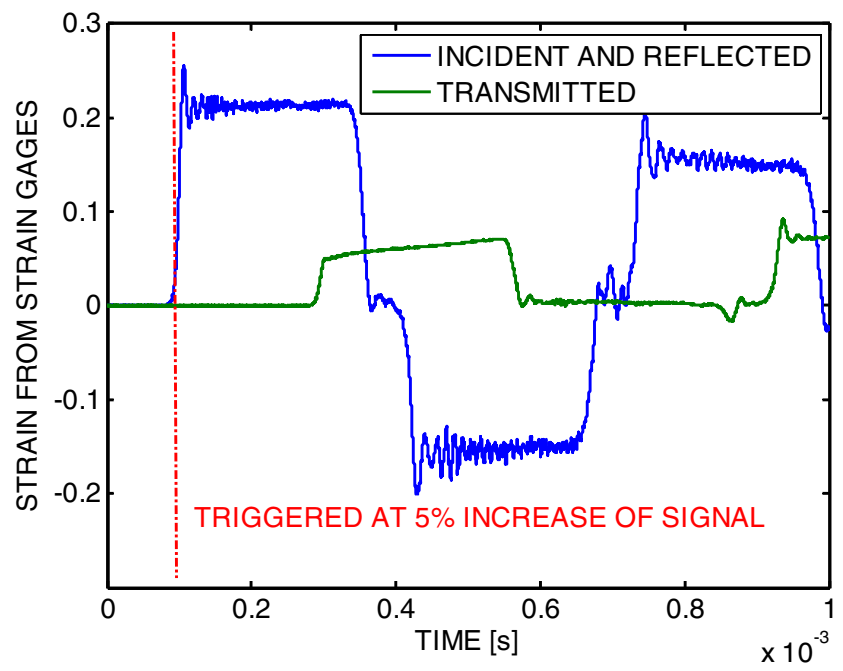

Fig. 10 Signals and trigger point in the SHPB test for OFHC copper specimen \#1 in the cold work condition before synchronization

\section{Numerical Simulation}

The simulation is based on the SHPB in our laboratory and performed by commercial software ABAQUS Explicit 6.7-1, which takes wave propagation effect into account [24]. The whole virtual assembly in ABAQUS consists of three parts: incident bar, transmitted bar and the specimen. The only difference from the real setup in our laboratory (Fig. 9) is that a step stress impulse is applied at the end of the incident bar in the axial direction instead of the striker with length $L_{s}$ and velocity $V$. The impulse loading on the incident bar in the axial direction is shown in Fig. 16, which is equivalent to a $618 \mathrm{~mm}$ striker with a velocity of $20 \mathrm{~m} / \mathrm{s}$, and the amplitude and duration of which can be calculated from equations (1) and (2).

In the simulation, an elastic steel model is defined for the bars and two elastic-plastic models are defined for the two types of OFHC copper: in the cold work condition and after total annealing (each type OFHC copper is simulated separately) by using the material model in Fig. 7. Three types of constraints are defined for the three parts to assemble the whole setup: Parallel Face, Face to Face and Coaxial. Both of the contacts (between incident bar and specimen; between transmitted bar and specimen) are defined by penalty contact method, of which tangential behavior is Frictionless and normal behavior is Hard

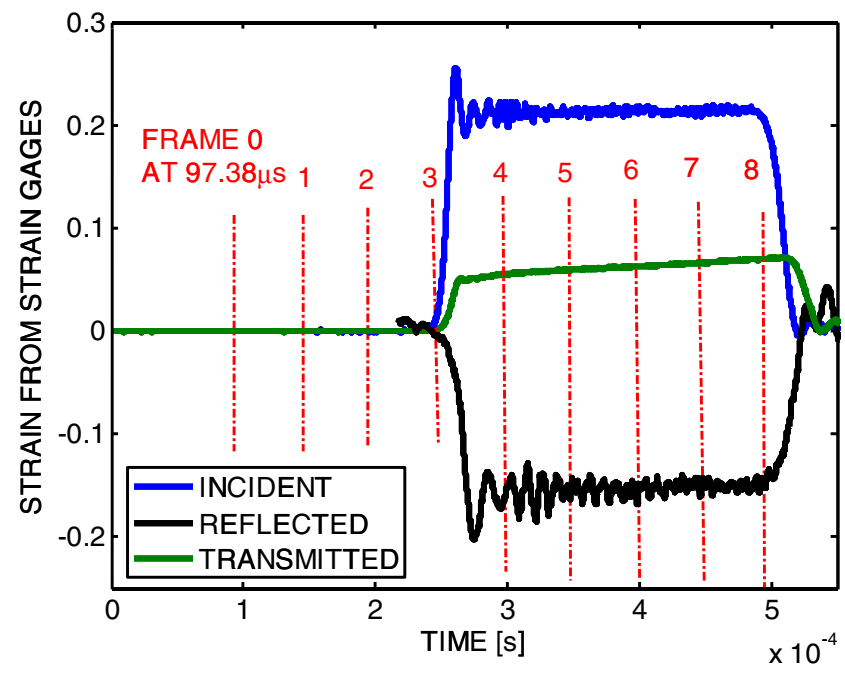

Fig. 11 Synchronized SHPB Signals with camera frames for OFHC copper specimen in the cold work condition (Specimen \#1). $\Delta \mathrm{t}$ between frames (red dash-dot lines) is $50 \mu \mathrm{s}$ 


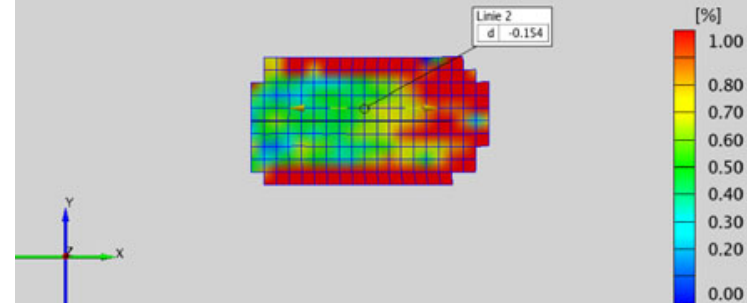

(a) Frame 3, t=247.38 $\mu \mathrm{s}$

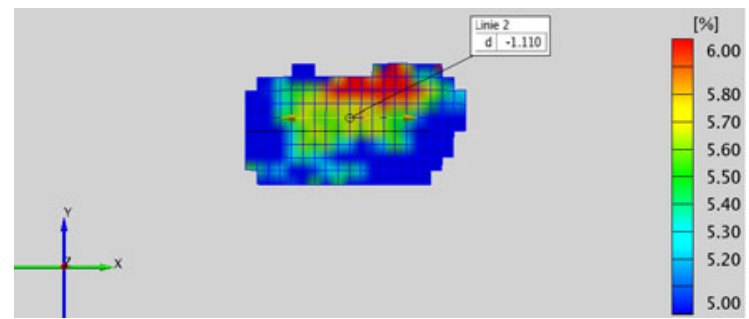

(c) Frame 5, $t=347.38 \mu \mathrm{s}$

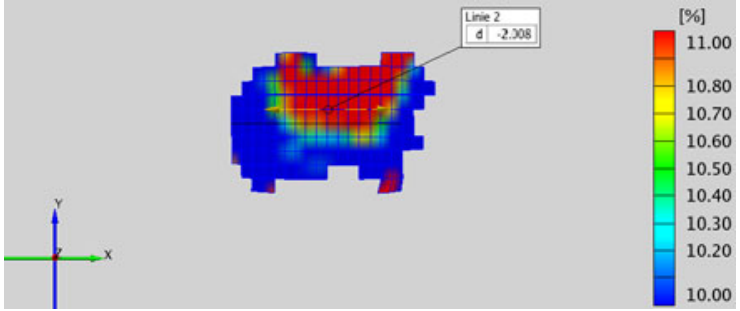

(e) Frame 7, t=447.38 $\mu \mathrm{s}$

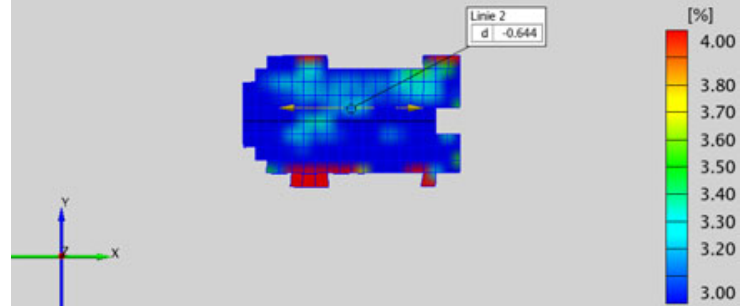

(b) Frame 4, t=297.38 $\mu \mathrm{s}$

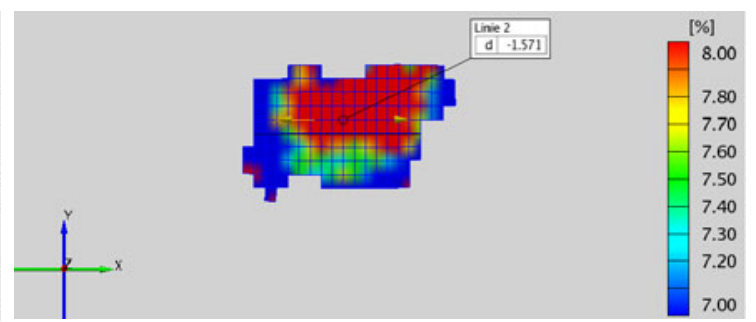

(d) Frame 6, t=397.38 $\mu \mathrm{s}$

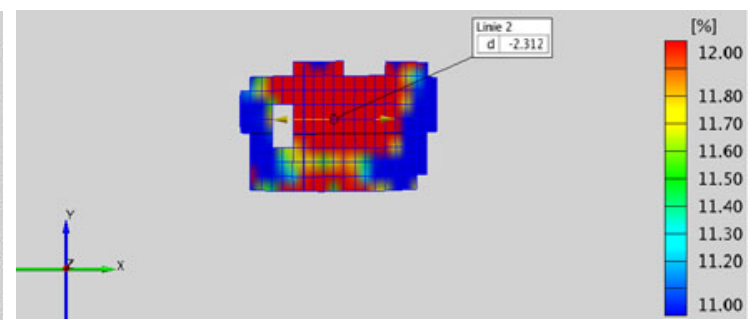

(f) Frame 8, t=497.38 $\mu \mathrm{s}$

Fig. 12 Half cylindrical strain field of the compression specimen \#1 with a $50 \mu$ s time step

Contact. The dimensions and technique parameters in the simulation are given in Table 4.

Since here our task is to investigate the specimen's plastic deformation and the effect of plastic wave propagation, failure of specimen's material model wasn't considered in the simulation (actually these two types of OFHC copper specimens do not fail in the real SHPB test). On the other hand, strain rate effects on material behavior of the specimens is also
Fig. 13 The strain distribution of the pixel path along specimen length in the cold work condition ( $\mathrm{x}$ axis is the pixels normalized by specimen's length, it's always from 0 to 1 nevertheless specimen's plastic deformation level). Solid curves are results of frame 3 to frame 9 for specimen $\# 3$, of which $\Delta \mathrm{t}$ is $50 \mu$ s. Dashed curves are results of specimen $\# 1, \# 2$, \#4 and $\# 5$, of which $\Delta \mathrm{t}$ is $10 \mu \mathrm{s}$

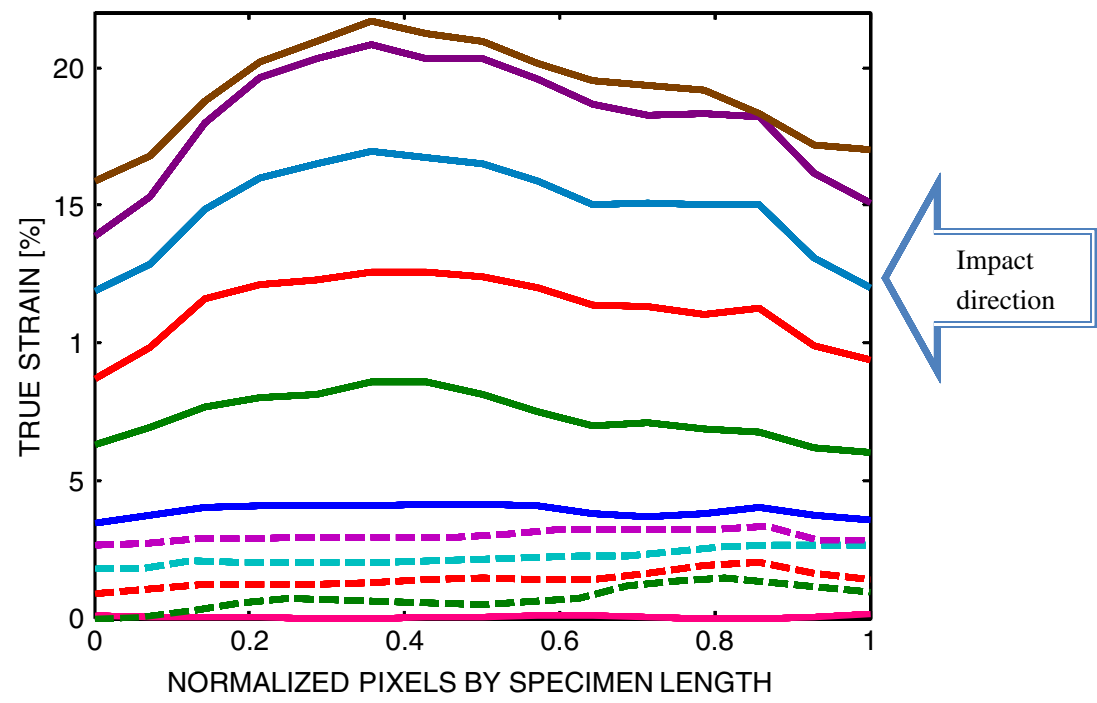




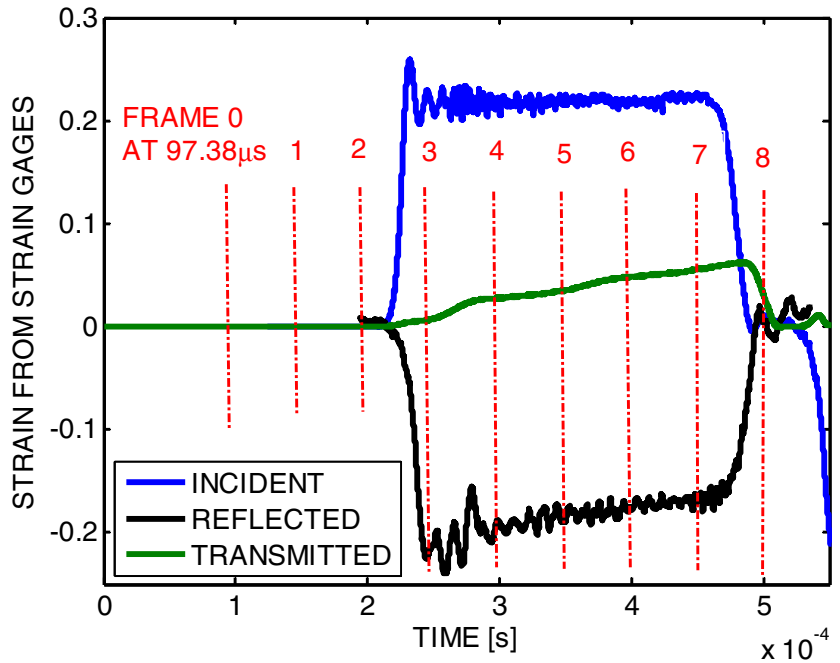

Fig. 14 Synchronized SHPB Signals with camera frames for OFHC copper specimen after total annealing (Specimen \#9). $\Delta \mathrm{t}$ between frames (red dash-dot lines) is $50 \mu \mathrm{s}$

ignored; i.e. strain rate hardening was not included in material model for the sake of constant nominal strain rate in the SHPB test.

To compare with results from the digital camera, a nodal point path (shown in Fig. 17) is also defined along the specimen length ( $z$ axis direction) for each simulation, which corresponds to the pixel path in the previous experimental half cylindrical strain field. The historical plastic strain distribution in the $z$ axis direction is recorded and plotted as normalized specimen length in Figs. 18 and 19 for these two types of OFHC copper specimens with a $10 \mu$ s time interval. Since numerical simulation strictly obeys Von Karman's plastic wave theory, there is a very low plastic wave velocity for OFHC copper specimens in

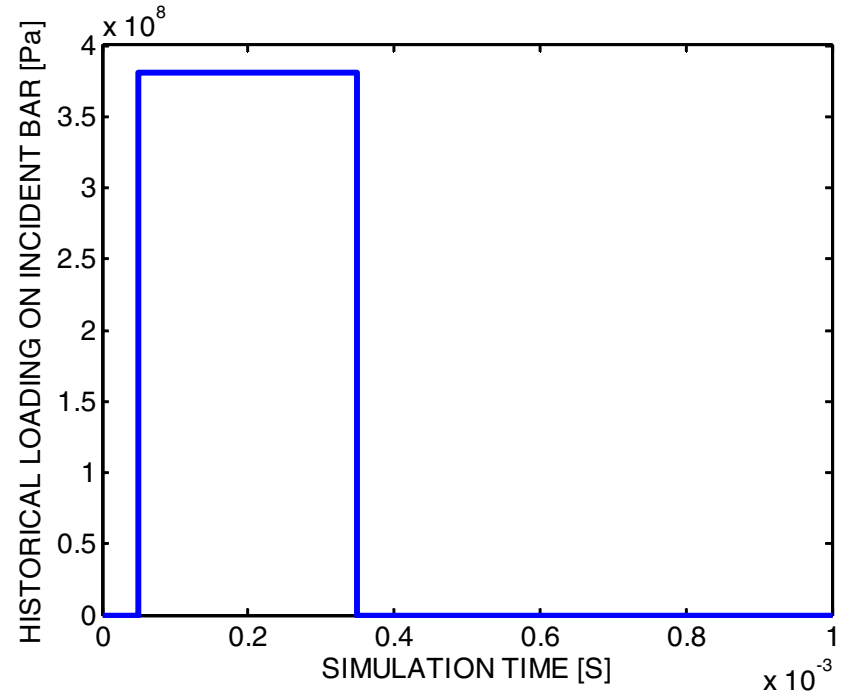

Fig. 16 Compression loading on the incident bar in the numerical simulation (note: the value should be negative, if the loading direction is taken into account)

the cold work condition (Fig. 8). So in Fig. 18, the specimen's deformation is quite non-uniform along its length and the plastic strain on the specimen incident side is always larger than that in specimen transmitted side. This non-uniform strain distribution becomes more and more severe as the strain lever becomes larger, and finally the cross section of the specimen changes from a rectangular shape to a trapezoidal shape. By contrast, there is a relatively high plastic wave velocity $(400 \mathrm{~m} / \mathrm{s}$ to $600 \mathrm{~m} / \mathrm{s})$ for OFHC copper specimens after total annealing heat treatment. The propagation and reflection of plastic waves along the specimen length are clearly shown in Fig. 19, thus the plastic strain distribution along specimen length is
Fig. 15 The strain distribution of the pixel path along specimen length after total annealing heat treatment ( $\mathrm{x}$ axis is the pixels normalized by specimen length, it's always from 0 to 1 nevertheless specimen's plastic deformation level). Solid curves are results of frame 3 to frame 9 for specimen $\# 9$, of which $\Delta \mathrm{t}$ is $50 \mu$ s. Dashed curves are corresponding results of specimen $\# 6, \# 7$, \#8 and \#10, of which $\Delta \mathrm{t}$ is $10 \mu \mathrm{s}$

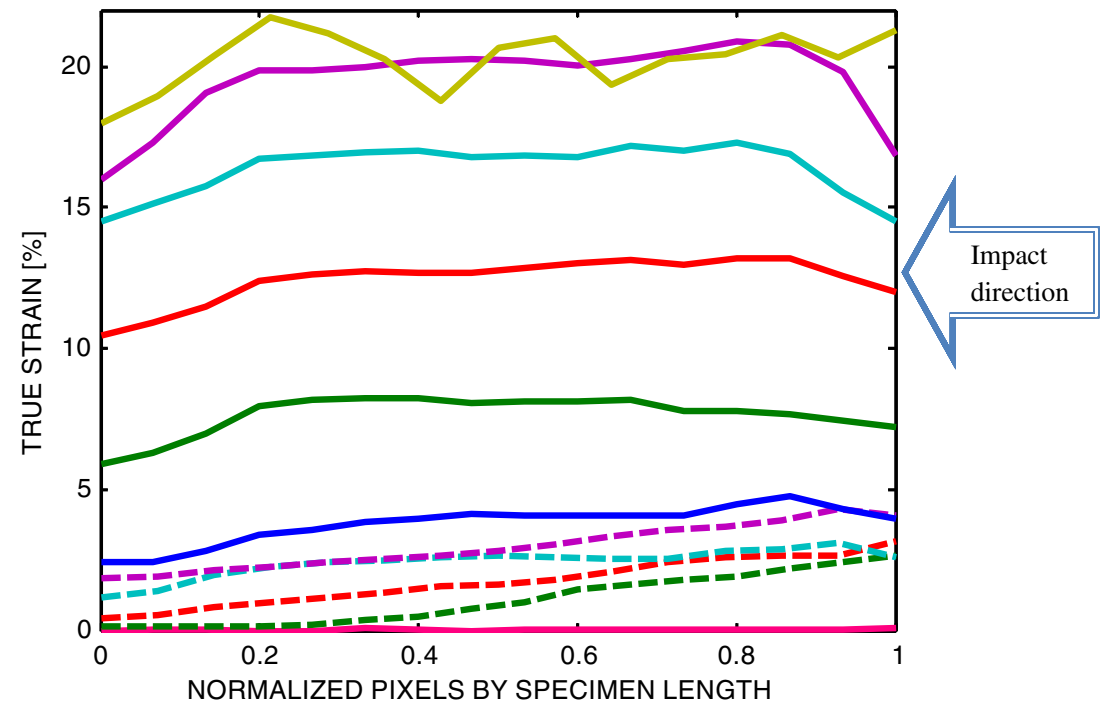


Table 4 Parameters of the numerical model in the simulation

\begin{tabular}{|c|c|c|c|c|c|c|}
\hline Part & Material & $\begin{array}{l}\text { Diameter } \\
{[\mathrm{mm}]}\end{array}$ & $\begin{array}{l}\text { Length } \\
{[\mathrm{mm}]}\end{array}$ & Section & $\begin{array}{l}\text { Element } \\
\text { type }\end{array}$ & $\begin{array}{l}\text { Mesh } \\
\text { sides [mm] }\end{array}$ \\
\hline Incident bar & Maraging & 19.7 & 1475 & Bar & 3D stress & 0.8 \\
\hline Transmitted bar & Maraging & 19.7 & 1475 & Bar & $3 \mathrm{D}$ stress & 0.8 \\
\hline Specimen 1 & OFHC copper in the cold work condition & 10 & 20 & Specimen & $3 \mathrm{D}$ stress & 0.2 \\
\hline Specimen 2 & OFHC copper after total annealing & 10 & 20 & Specimen & 3D stress & 0.2 \\
\hline
\end{tabular}

much more uniform than that for OFHC copper in the cold work condition.

\section{Discussion}

In the first part of this paper, the incident stress impulse was investigated by elastic wave frequency analysis, since the whole procedure of its generation and propagation along the axial direction of the bar is totally elastic. It was found that rise time of the incident stress impulse is related to the radius and elastic longitudinal wave velocity of the bar from equation (12). In real experiments, there are differences between the incident stress impulse shapes from different SHPB facilities. One may think this difference is only due to the properties of the bar material or experimental conditions, but we clearly show that it's also dominated by bar radius, which determines the highest frequency components of elastic waves propagating along the bar with the elastic longitudinal velocity $[2,3,17-21]$. The shape of the incident stress impulse can be improved to a nearly perfect step impulse by reducing the bar radius. Furthermore, to build the force equilibrium in this time duration, a maximum allowable specimen length is given as a technique criterion for the SHPB test. The discussion here about the specimen length can explain Duwez and Clark's results on specimen length very well [22].

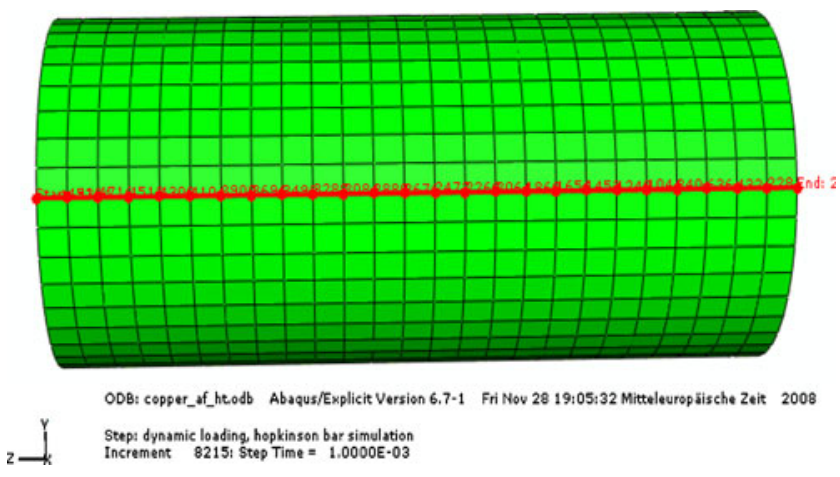

Fig. 17 Defined nodal point path on specimen cylindrical surface in the numerical simulation, which is along specimen length during the dynamic loading
Second, the data processing method of the SHPB test is re-examined by the introduction of Von Karman's plastic wave theory. A maximum allowable impact velocity (MAIV) for a striker is obtained as another technique criterion in the SHPB test. From Fig. 5, for soft testing material with a low yield stress, the effect of specimen diameter/radius is small on MAIV, but the value of MAIV is also very small. In addition, the experimental technique for soft materials (such as rubber, human tissue.) compared with metal was developed by Chen $[11,26]$. A standard steel SHPB with modified techniques had to be used to investigate rubber specimen's dynamic mechanical properties. Although the conception of elastic Young's modulus and yield stress aren't appropriate parameters for these soft materials, the above conception of MAIV also has something meaningful in explaining the difficulties of the SHPB test. Compared with bar material, the plastic flow stress of the soft material is far less than that of steel. So the value of MAIV is rather small, no matter what the specimen geometry is. The plastic deformation of the incident side of specimen always takes place earlier than that of the transmitted side. Auxiliary facility has to be introduced to overcome the difficulty $[11,26]$.

Although previous results are generally based on SHPB tests in compression, MAIV can also be extended to the tension and torsion cases. Especially the SHPB tension test, sometimes, the specimen necks near the incident side at the beginning of the dynamic loading, which is called early necking, when the material of specimen is rather soft. MAIV can explain such phenomenon as being mainly due to the low yield stress of the tested material and too high an impact velocity. Furthermore, for brittle materials such as ceramics with a high yield stress [25], the specimen geometry becomes a key factor for validation of the SHPB test as well as the striker's impact velocity.

Third, an SHPB experiment with high speed camera was designed to record the plastic wave propagation along a specimen length by using two kinds of OFHC copper specimens: (i) in the cold work condition and (ii) after total annealing, and whose length was longer than the theoretical maximum allowable length, and for which impact velocity of the striker was higher than the MAIV. From Figs. 13 and 15 , for both kinds of material, plastic wave propagation 
Fig. 18 Historical plastic strain along specimen length direction (the nodal point path defined in Fig. 17) for OFHC copper specimen in the cold work condition from numerical simulation (Time between curves is $10 \mu \mathrm{s}$ )

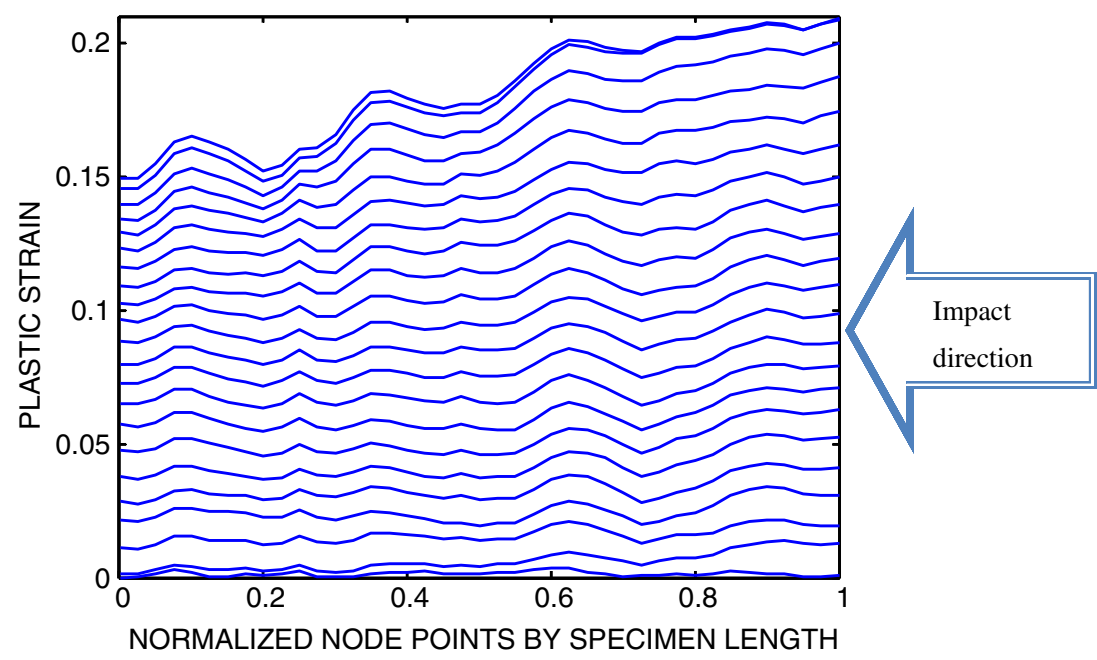

along specimen length (the non-uniform plastic deformation) can be observed when the specimens just began plastic deformation. As the plastic strain level increased, the plastic strain along the specimen length was rather uniform, and no motion (propagation and reflection) of plastic wave was detected either for the strain hardening material or for the non strain hardening material. The above experimental results can verify previous researchers' observation [3032]. When the plastic strain level became more than $10 \%$, side confinement effect of the friction between specimen and bars became evident, which has a significant influence on material's behavior under dynamic loading and failure model [27-29].

Fourth, numerical simulation showed the plastic strain distributions along the specimen length are quite different for OFHC copper specimens in the two conditions. For strain hardening material, i. e. OFHC copper after total annealing heat treatment, the propagation and reflection of plastic wave along specimen length obviously existed at large strain, as it has a relatively high plastic wave velocity. For non strain hardening material, i.e. OFHC copper in the cold work condition, the plastic strain was rather non uniform along the specimen length; the incident side of specimen always had a larger plastic strain than on the transmitted side. These differences between experimental and numerical results call our attention to the validation of plastic wave theory. In fact, the theory has two fundamental simplifying assumptions. First there is no strain rate effect in the stress-strain behavior of the material. The other is that the lateral or radial motion of the material can be neglected [33]. But in the experiment, with a large plastic strain specimen, the radial motion of the specimen can't be neglected, so the plastic wave theory can't be applied any more. This is why experimental results are different from numerical simulation. In addition, the side confinement effect of friction in the SHPB test makes the one
Fig. 19 Historical plastic strain along specimen length direction (the nodal point path defined in Fig. 17) for OFHC copper specimen after total annealing from numerical simulation (Time between curves is $10 \mu \mathrm{s}$ )

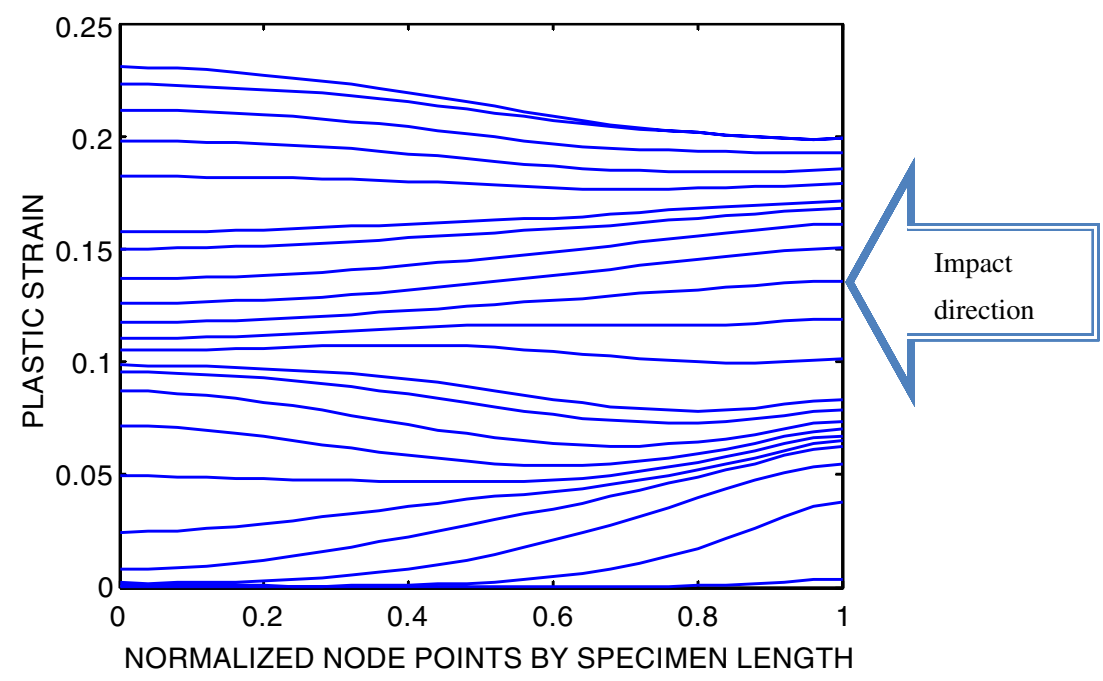


dimensional assumption no longer valid, which may be another reason that Von Karman's theory does not hold.

Here we have to mention Klepaczko's theory of critical impact velocity (CIV), which is the criterion of a material's adiabatic thermal instability under dynamic loading [34]. From the above analysis, the CIV maybe is not suitable for large failure strain materials, since the plastic wave theory is no longer applicable.

One may think that the non-uniform plastic strain distribution along specimen's length, which is observed in the SHPB test, may be from the oscillations on the incident impulse. But from Figs. 11 and 14, for the frame 4, when ringing has really attenuated, there is still a non uniform strain distribution along the specimen length (Figs. 13 and 15).

\section{Conclusion}

The data processing method of SHPB test is re-investigated by introduction of plastic wave theory. An experimental setup is designed with a SHPB facility and a high speed digital camera by using OFHC copper specimens in two conditions: in the cold work condition and after total annealing heat treatment. Numerical simulation is also done by commercial software ABAQUS Explicit 6.7-1 as an auxiliary method to compare with experimental results. The following conclusions can be drawn:

- The rise time of an incident impulse in SHPB test is related to the bar's radius/diameter and elastic longitudinal velocity, which can be shorter by reduction of the bar's radius/diameter;

- The maximum allowable specimen length is given as a technique criterion of the SHPB test;

- The maximum allowable impact velocity (MAIV) of striker can be considered as a technique criterion for a specific material in SHPB test;

- The propagation of plastic wave is observed along specimen length at the beginning of specimen's plastic deformation in SHPB test. However, no more wave motions can be experimentally caught at large plastic strain levels, whether the specimen material strain hardens or not. Plastic wave theory is experimentally proved to be only valid at low plastic strain level.

- Side confinement effect of friction between bars and specimen may play an important role for material's behavior under dynamic loading in the case of large plastic strain, even if lubricant is used.

Acknowledgements This work was supported by DFG through a grant ME 1457/12-3 to Prof. Dr. Dr. h.c. L. W. Meyer at Chemnitz University of Technology.
Open Access This article is distributed under the terms of the Creative Commons Attribution Noncommercial License which permits any noncommercial use, distribution, and reproduction in any medium, provided the original author(s) and source are credited.

\section{References}

1. Hopkinson B (1914) A method of measuring the pressure produced in the detonation of high explosives or by the impact of bullets. Philos Trans R Soc 213:437-452

2. Kolsky H (1949) An investigation of the mechanical properties of materials at very high rates of loading. Proc Phys Soc Section B 62(11):676-700

3. Davies RM (1948) A critical study of the Hopkinson pressure bar. Phil Trans Roy Soc London 240:375-457

4. Taylor GI (1958) Plastic wave in a wire extended by an impact load, Scientific papers, Vol. 1 mechanics of solids. Cambridge University Press, Cambridge, p 456

5. Davies ED, Hunter SC (1962) The dynamic compression testing of solids by the method of the split Hopkinson pressure bar. J Mech Phys Solids 11:155-179

6. Lindholm US (1964) Some experiments with the split Hopkinson pressure bar. J Mech Phys Solids 12:317-335

7. Follansbee PS (1985) The Hopkinson bar, mechanical testing, metals handbook. 8: 198-217

8. Nemat-Nasser S, Isaacs JB, Starrett JE (1991) Hopkinson techniques for dynamic recovery experiments. Proc R Soc A 435:371-391

9. Meyer LW, Staskewitsch E, Burblies A (1994) Adiabatic shear failure under biaxial dynamic compression/shear loading. Mech Mater 17(2-3):203-214

10. Lennon AM, Ramesh KT (1998) A technique for measuring the dynamic behavior of materials at high temperatures. Int J Plast 14:1279-1292

11. Chen WW, Lu F, Zhou B (2000) A quartz-crystal-embedded split Hopkinson press bar for soft materials. Exp Mech 10(1):1-6

12. Field JE, Walley SM, Proud WG, Goldrein HT, Siviour CR (2004) Review of experimental techniques for high rate deformation and shock studies. Int J Impact Eng 30:725-775

13. Jordan JL, Siviour CR, Foley JR, Brown EN (2007) Compressive properties of extruded polytetrafluoroethylene. Polymer 48:4184-4195

14. Karman T, Duwez P (1950) The propagation of plastic deformation in solids. J Appl Phys 21:987-995

15. Conn AF (1965) On the use of thin wafers to study dynamic properties of metals. J Mech Phys Solids 13:311-327

16. Wood ER, Phillips A (1967) On the theory of plastic wave propagation in a bar. J Mech Phys Solids 15:241-254

17. Chree C (1886) Longitudinal vibrations of a circular bar. Quarterly Journal of Pure and Applied Mathematics 21:287-298

18. Chree C (1889) The equations of an isotropic elastic solid in polar and cylindrical coordinates: their solution and application. Transactions of the Cambridge Philosophical Society 14:250-369

19. Chree C (1890) On the longitudinal vibrations of aelotropic bars with one axis of material symmetry longitudinal vibrations of a circular bar. Quarterly Journal of Pure and Applied Mathematics 24:340-359

20. Chree C (1890) Longitudinal vibrations in solid and hollow cylinders. Proc Phys Soc London 16:304-322

21. Pochhammer L (1876) Über Fortpflanzungsgeschwindigkeiten kleiner chwingungen in einem unbegrenzten isotropen Kreiszylinder. Journal für die Reine und Angewandte Mathematik 81:324-336

22. Duwez PE, Clark DS (1947) An experimental study of the propagation of plastic deformation under conditions of longitudinal impact. Process of ASTM 47:502-521 
23. Armstrong RW, Walley SM (2008) High strain rate properties of metals and alloys. Int Mater Rev 53(3):105-128

24. User's Manual of ABAQUS Explicit 6.7-1, SIMULIA (2007)

25. Chen W (1995) Dynamic failure behavior of ceramics under multi-axial compression. Ph. D. thesis, Caltech. http://etd.caltech. edu/etd/available/etd-11032003-101839/

26. Song B, Chen W (2004) Dynamic stress equilibration in split Hopkinson pressure bar tests on soft materials. Exp Mech 44 (3):300-312

27. Walley SM, Field JE, Pope PH, Safford NA (1989) A study of the rapid deformation behavior of a range of polymers. Philos Trans $\mathrm{R}$ Soc 328(1989):1-33

28. Rittel D, Hanina E, Ravichandran G (2008) A note on the direct determination of the confining pressure of cylindrical specimens. Exp Mech 48(3):375-377
29. Rittel D, Brill A (2008) Dynamic flow and failure of confined polymethylmethacrylate. Journal of Mechanics and Physics of Solids 56(4): 1401-1416

30. Gorham DA (1979) Measurement of stress-strain properties of strong metals at very high rates of strain. Inst Phys Conf Ser 47:16-24

31. Gilman JJ (1992) The plastic wave myth in Shock Compression of Condensed Matter (ed) Schmidt SC et al. publication Elsevier, pp 387-389

32. Siviour CR (2009) A measurement of wave propagation in the split Hopkinson pressure bar. Meas Sci Technol 20:065702

33. Hauser FE, Simmons JA, Dorn JE (1960) Strain rate effects in plastic wave propagation, response of metals to high velocity deformation. Interscience, New York, pp 93-114

34. Klepaczko JR (2005) Review on critical impact velocities in tension and shear. Int J Impact Eng 32:188-209 